\title{
Hydrodynamics behaviour of slot-rectangular spouted beds: assessment of slot width effect
}

\author{
E. Esmaili ${ }^{1}$, N. Mahinpey ${ }^{1}$ \& C. J. Lim ${ }^{2}$ \\ ${ }^{1}$ Dept. of Chemical and Petroleum Engineering, \\ Schulich School of Engineering, University of Calgary, Canada \\ ${ }^{2}$ Dept. of Chemical and Bio-Resources Engineering, \\ University of British Columbia, Vancouver, Canada
}

\begin{abstract}
Spouted beds, originally invented in Canada (1955), have been widely used in drying, granulation, catalytic polymerization, residue treatment and coating of several materials. Understanding of gas and particle hydrodynamics behavior in a slot-rectangular spouted bed is important for evaluation of particle circulation rate and gas-solid contact efficiency and also for overcoming scale-up difficulties. Although have been extensively applied, the mechanisms of solid movement in spouted beds are still not completely understood. In this research, computational fluid dynamics (FLUENT 6.3) has been used to perform a complete study on the hydrodynamic behavior of spouted bed using an EulerianEulerial two-phase model. The Eulerian model assumes that both phases can be considered as fluid and also take the interpenetrating effect of each phase into consideration by using inter-phase drag models. The computational work has been significantly reduced using a 2D axisymmetric mesh for the bed, operating at different conditions (i.e. different superficial gas velocities, static bed heights, size of particle). Furthermore, the effect of slot width on the hydrodynamic behavior of the bed has been predicted. The results predicted by numerical simulation have been validated with the earlier experiments conducted. The comparisons have been made in terms of fountain height for various operating conditions. The results show a good agreement between the experimental data and the numerical simulation.
\end{abstract}

Keywords: spouted beds, slot-rectangular, computational fluid dynamics, FLUENT. 


\section{Introduction}

Since its discovery by Mathur and Gishler [2], cylindrical-conical spouted beds have been used in a number of applications such as gas-solid catalytic reactions, coal gasification, drying of pastes and grains, particle mixing, tablet coating and granulation [3]. However, the spouted bed technique has seldom been applied in large scale industrial processes due to certain limitations, in particular scale-up difficulties [4] such as instability to achieve good quality spouting in large scale vessels, and difficulties in predicting the performance of spouted beds larger than $0.3 \mathrm{~m}$ in diameter [1].

Conventional spouted beds consist of a cylindrical column with a conical base where the bed of particles is spouted by the injection of air through a circular orifice at the bottom. The flow structure of spouted beds is quite different from fluidized beds. At stable spouting, a spouted bed consists of three regions, a spout in the center, a fountain above the bed surface and an annulus between the spout and the wall, Figure 1. The behavior of spout and the fountain is similar to fluidized beds with particles dynamically suspended, while the annulus region is more like a packed bed or moving bed. It is generally believed that in the annulus, particles move vertically downward and the radially inward, following approximately parabolic paths [3]. The pressure drop of a conical spouted bed under stable spouting condition is about $40 \%$ of a fluidized bed with the same static bed height $[5,6]$. This suggests that particles are not in a fully suspended state at stable spouting.

As an alternative to units of circular cross-section, Mujumdar and colleagues $[4,7,8]$ suggested a spouted bed of rectangular cross-section to eliminate the

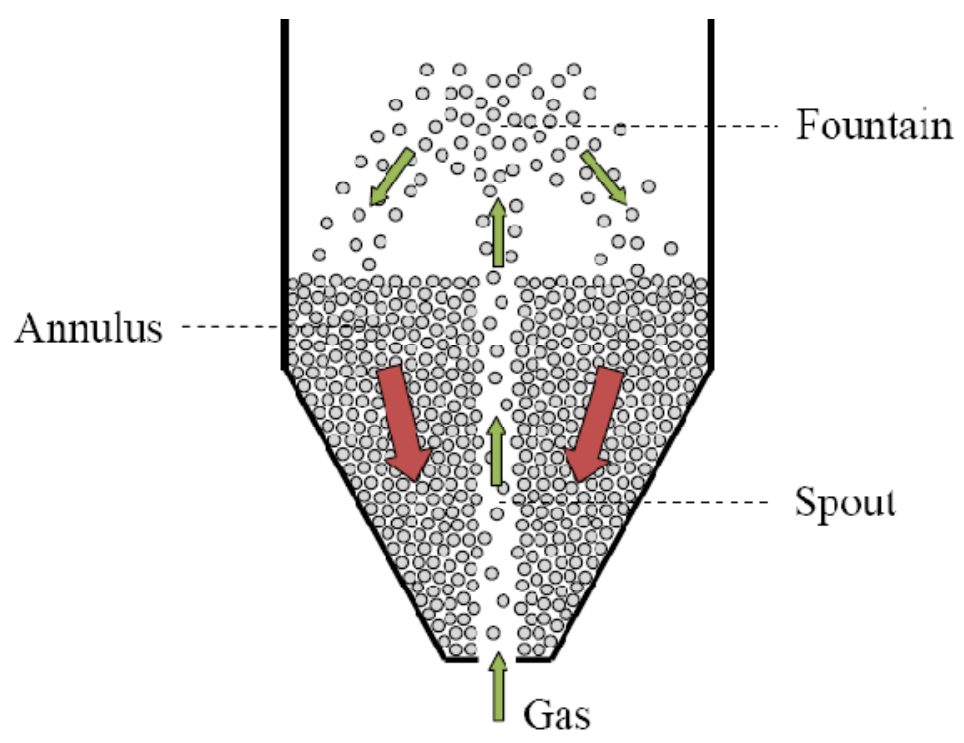

Figure 1: Schematic of a spouted bed operating in stable condition. 
scale-up disadvantages of conventional spouted beds. In this configuration the column has vertical plane walls and a diverging base on two opposite sides, while the other two opposing faces are both completely vertical. The spouting air enters through a horizontal slot at the bottom of the two diverging plane surfaces. Scaling up of the slot-rectangular columns can be achieved by simply moving the facing vertical walls further apart, or combining small units by sharing either the front and back faces or the sidewalls. A schematic diagram of this geometry is shown in Figure 2.

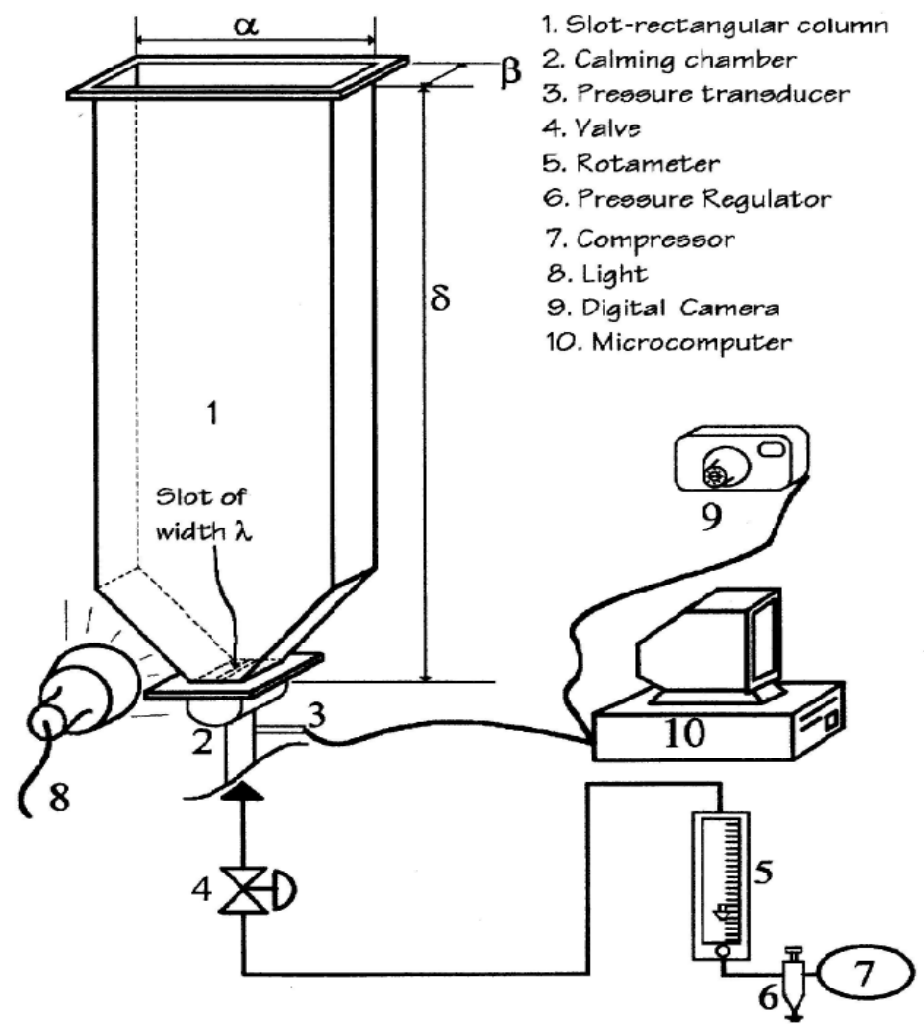

Figure 2: $\quad$ Schematic of the experimental apparatus.

The numerical simulation technique and computational fluid dynamics (CFD) studies have become popular in the field of gas-solid two-phase flow. Many researchers have applied the numerical simulation as a useful tool to obtain detailed information about flow phenomena without disturbing them [9-14]. Shirvanian et al. [15] developed a three dimensional Eulerian simulation to predict the manner in which particle size, density, loading, and inlet jet velocity affect solids circulation in a rectangular spouted vessel. Their model is shown to be able to successfully predict the experimentally observed phenomenon of particle "choking" where the particle recirculation rate remains constant with increasing particle loading once a "critical loading" is achieved. Their 
simulations also showed "mounding" of the particles on the outside of the draft duct walls near the inlet at high solids loadings, which would tend to reduce the effectiveness of metal recovery. This condition can be minimized or prevented by reducing the solids loading and operating at lower fluid flow rates to increase the particle circulation rate.

Bettega et al. [16] performed a numerical study of the scale-up of spouted beds. Their results verified that the scale-up relationships of He et al. [17] were well represented by CFD simulations, indicating the capability of this tool to evaluate similitude method. They concluded that, when the full set of scaling relationships are not satisfied, important disturbances appears in the hydrodynamic of scaled equipments and make the spouted bed to extinguish. These behaviours are the result of an overestimation or underestimation of velocity in the entrance, respectively, when the whole set of dimensionless parameters is not matched.

Sobieski [18] developed a computer model for an actual spouted bed grain dryer to study the response of the Eulerian multiphase model to changes in values of its parameters. The fountain height was assumed to be the basic value characterizing the bed during operation. His results verified that the Eulerian multiphase model can be used for the simulation of the hydrodynamics of spouted-bed grain dryers. He also concluded that higher quantitative match of experimental results with computations (particularly as concerns the internal bed dynamics) can be obtained by appropriate choice of the turbulence model.

The present work is based on the earlier experiments conducted by Dogan et al. [1]. A numerical simulation of slot rectangular spouted bed has been presented to study the effect of slot width on the hydrodynamic behavior of the bed. FLUENT 6.3.26 has been used to perform the numerical simulations based on an Eulerian-Eulerian two phase model. Adjusted Di Felice drag model [19] has been used to take the interpenetrating effect of each phase into consideration. The results have been presented in terms of the fountain height for various operating conditions (i.e. different superficial gas velocities, static bed heights, and size of particle).

\section{Experimental setup}

The experiments were carried out by Dogan et al. [1] in a Plexiglas rectangular column of cross-sectional dimensions $\alpha=150 \mathrm{~mm}$ and $\beta=29 \mathrm{~mm}$ with an overall height $\delta=700 \mathrm{~mm}$ (see Figure 2). The included angle of the diverging lower section, $\theta$, was $30^{\circ}$. Air entry slots of length equal to $\beta$ and widths, $\lambda=2,6,10$ and $20(\mathrm{~mm})$ were used in the experiments. A fine wire mesh was inserted across these slots to prevent particles from falling into the air pipe. A calming chamber was installed below the air entry slots to regulate and smooth the air flow. The fountain height, $\mathrm{H}_{\mathrm{F}}$, was measured with a ruler taped to the column wall. A summary of the experimental conditions studied in this work is presented in Table 1 . The particles used in their experiments were closely sized glass beads of three different diameters and low density polyethylene. The particle characteristics and key dimensions are listed in Table 2. 
Table 1: $\quad$ Experimental conditions.

\begin{tabular}{cc}
\hline Column width, $\alpha(\mathrm{m})$ & 0.15 \\
Column thickness, $\beta(\mathrm{m})$ & 0.029 \\
Slot width, $\lambda(\mathrm{m})$ & $0.002-0.02$ \\
Bed height, $\mathrm{H}_{\mathrm{o}}(\mathrm{m})$ & $0.03-0.3$ \\
Air flow rate, $\left(\mathrm{m}^{3} / \mathrm{s}\right)$ & $0-0.015$ \\
\hline
\end{tabular}

Table 2: $\quad$ Particle properties.

\begin{tabular}{cccccc}
\hline Particles & $d_{P}(\mathrm{~mm})$ & $\rho_{S}\left(\mathrm{~kg} / \mathrm{m}^{3}\right)$ & $\varepsilon_{b}(-)$ & $U_{m f}(\mathrm{~m} / \mathrm{s})$ & $U_{T}(\mathrm{~m} / \mathrm{s})$ \\
\hline Glass beads & 0.86 & 2520 & 0.385 & 0.44 & 7.8 \\
Glass beads & 1.44 & 2520 & 0.385 & 0.62 & 10.2 \\
Glass beads & 2.28 & 2520 & 0.390 & 1.48 & 12.8 \\
Polyethylene & 3.77 & 940 & 0.392 & 0.80 & 8.3 \\
\hline
\end{tabular}

\section{Governing equations}

A "two-fluid" (fluid and solid phases), Eulerian-Eulerian model was developed to simulate the hydrodynamics of a rectangular spouted bed [19]. The governing equations of the model have been summarized in Table 3.

Table 3: $\quad$ Governing equations.

\begin{tabular}{|c|c|}
\hline \multicolumn{2}{|l|}{ Continuity: } \\
\hline$\frac{\partial}{\partial t}\left(\varepsilon_{q} \rho_{q}\right)+\nabla \cdot\left(\varepsilon_{q} \rho_{q} \vec{V}_{q}\right)=0, \quad q=s$ or $g$ & (1) \\
\hline \multicolumn{2}{|l|}{ Momentum equations: } \\
\hline$\frac{\partial}{\partial t}\left(\varepsilon_{g} \rho_{g} \vec{V}_{g}\right)+\nabla \cdot\left(\varepsilon_{g} \rho_{g} \vec{V}_{g} \vec{V}_{g}\right)=\nabla \cdot \overline{\bar{\tau}}_{g}-\varepsilon_{g} \nabla P+\varepsilon_{g} \rho_{g} g+K_{s g}\left(\vec{V}_{s}-\vec{V}_{g}\right)$ & $(2)$ \\
\hline $\begin{aligned} \frac{\partial}{\partial t}\left(\varepsilon_{s} \rho_{s} \vec{V}_{s}\right)+\nabla \cdot & \left(\varepsilon_{s} \rho_{s} \vec{V}_{s} \vec{V}_{s}\right) \\
& =\nabla \cdot \overline{\bar{\tau}}_{s}-\nabla P_{s}-\varepsilon_{s} \nabla P+\varepsilon_{s} \rho_{s} g+K_{s g}\left(\vec{V}_{s}-\vec{V}_{g}\right)\end{aligned}$ & (3) \\
\hline Stress tensors & \\
\hline $\begin{array}{c}\overline{\bar{\tau}}_{g, \text { eff }}=\varepsilon_{g}\left(\overline{\bar{\tau}}_{g}+\overline{\bar{\tau}}_{t}\right) \\
\overline{\bar{\tau}}_{g}=\mu_{g}\left(\nabla \vec{V}_{g}+\left(\nabla \vec{V}_{g}\right)^{T}\right)-\frac{2}{3} \mu_{g} \overline{\bar{I}} \cdot \nabla \cdot \vec{V}_{g} \\
\overline{\bar{\tau}}_{t}=\mu_{t}\left(\nabla \vec{V}_{g}+\left(\nabla \vec{V}_{g}\right)^{T}\right)-\frac{2}{3} \mu_{t} \overline{\bar{I}} \cdot \nabla \cdot \vec{V}_{g}-\frac{2}{3} \varepsilon_{g} \rho_{g} k \overline{\bar{I}} \\
\overline{\bar{\tau}}_{s}=\varepsilon_{s} \mu_{s}\left(\nabla \vec{V}_{s}+\left(\nabla \vec{V}_{s}\right)^{T}\right)+\varepsilon_{s}\left(\lambda_{s}+\frac{2}{3} \mu_{s}\right) \nabla \cdot \vec{V}_{s} \overline{\bar{I}} \\
\mu_{s}=\frac{4}{5} \varepsilon_{s}{ }^{2} \rho_{s} d_{s} g_{0}(1+e) \sqrt{\frac{\Theta}{\pi}}+\frac{\frac{5 \sqrt{\pi}}{48} \rho_{s} d_{s} \sqrt{\Theta}}{(1+e) g_{0}}\left[1+\frac{4}{5} g_{0} \varepsilon_{s}(1+e)\right]^{2} \\
\lambda_{s}=\frac{4}{3} \varepsilon_{s}{ }^{2} \rho_{s} d_{s} g_{0}(1+e) \sqrt{\frac{\Theta}{\pi}}\end{array}$ & (9) \\
\hline
\end{tabular}


Table 3: $\quad$ Continued.

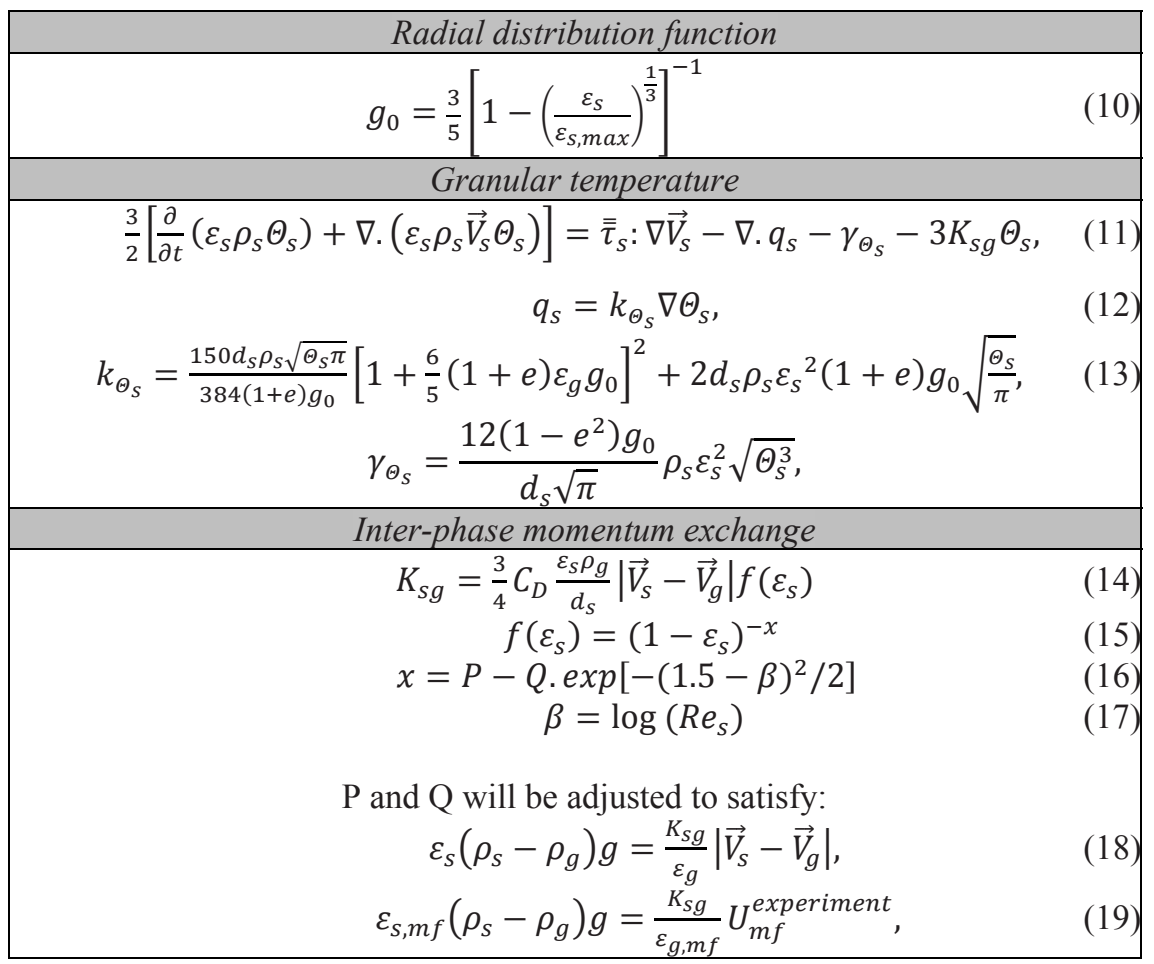

\section{Numerical simulation}

Governing equations of mass and momentum conservation as well as the granular temperature equation are solved using finite volume method employing the Phase-Coupled Semi Implicit Method for Pressure Linked Equations (PCSIMPLE) algorithm, which is an extension of the SIMPLE algorithm to multiphase flow. A two-fluid Eulerian-Eulerian model, which considers the conservation of mass and momentum for each phase, has been applied. The adjusted Di Felice drag model [19] has been implemented to include the momentum transfer between the phases. The $2 \mathrm{D}$ axisymmetric computational domain has been meshed with unstructured triangular cells in the cone base and structured square cells in the rest of the domain. GAMBIT 2.13 has been used for meshing the geometry, Figure 3. The mesh was generated using node spaces of larger than the particle diameter. Volume fraction, density, and pressure are stored at the main grid points that are placed in the center of each control volume. A staggered grid arrangement is used, and the velocity components are solved at the control volume surfaces. A pressure correction equation is built based on total volume continuity. Pressure and velocities are then corrected so as to satisfy the continuity constraint. Second-order upwind discretization scheme 
was used for discretizing the partial differential equations. An adaptive timestepping algorithm with 100 iterations per each time step and a minimum value of $2 \times 10^{-4}$ (s) for the lower domain of time steps was used to ensure a stable convergence. The adaptive determination of the time step size is based on the estimation of the truncation error associated with the time integration scheme (i.e., first-order implicit or second-order implicit). If the truncation error is smaller than a specified tolerance, the size of the time step is increased; if the truncation error is greater, the time step size is decreased. The convergence criteria for other residual components associated with the relative error between two successive iterations has been specified in the order of $10^{-3}$. The discretized equations along with the initial and boundary conditions are solved using

Table 4: $\quad$ Computational model parameters.

\begin{tabular}{|c|c|c|}
\hline Parameter & \multicolumn{2}{|c|}{ Value/description } \\
\hline \multirow{3}{*}{ Bed dimension } & \multicolumn{2}{|c|}{$0.15 \times 0.029 \times 0.7(\mathrm{~mm}), \theta=30^{\circ}$} \\
\hline & Slot width & $0.002-0.02(\mathrm{~m})$ \\
\hline & Static bed height & $0.06-0.21(\mathrm{~m})$ \\
\hline Solver & \multicolumn{2}{|c|}{$\begin{array}{c}\text { Pressure based, unsteady, 2nd order Imp., } \\
\text { axisymmetric }\end{array}$} \\
\hline Multiphase flow model & \multicolumn{2}{|c|}{ Eulerian, 2-phase (air, particles) } \\
\hline Grid interval spacing & & $0.0025(\mathrm{~m})$ \\
\hline Time steps & \multicolumn{2}{|c|}{$0.0002(\mathrm{~s})$} \\
\hline \multirow[t]{3}{*}{ Discretization } & Momentum & 2nd order upwind \\
\hline & Volume fraction & QUICK \\
\hline & Turbulent & 2nd order upwind \\
\hline \multirow[t]{5}{*}{ Materials } & Particle density & $2520\left(\mathrm{~kg} / \mathrm{m}^{3}\right)$ \\
\hline & Gas density & $1.225\left(\mathrm{~kg} / \mathrm{m}^{3}\right)$ \\
\hline & Gas viscosity & 1.7894 \\
\hline & & $10^{-5}(\mathrm{~kg} / \mathrm{m} \cdot \mathrm{s})$ \\
\hline & Mean particle diameter & $0.86-3.77(\mathrm{~mm})$ \\
\hline \multirow[t]{4}{*}{ Phases } & Gas-solid drag model & Adjusted Di Felice \\
\hline & Res. coeff. & 0.95 \\
\hline & Initial solid packing & $0.385-0.392$ \\
\hline & Max. packing limit & 0.63 \\
\hline \multirow[t]{4}{*}{ Boundary conditions } & Inlet Velocity & $0.5-10(\mathrm{~m} / \mathrm{s})$ \\
\hline & Outlet & Pressure-outlet \\
\hline & Axis & Axisymmetric \\
\hline & Wall & Non-slip for the fluid \\
\hline \multirow{4}{*}{$\begin{array}{l}\text { Under-relaxation } \\
\text { factors }\end{array}$} & Pressure & 0.3 \\
\hline & Momentum & 0.4 \\
\hline & Volume fraction & 0.3 \\
\hline & Granular temperature & 0.2 \\
\hline Convergence criterion & & \\
\hline
\end{tabular}


FLUENT 6.3 on Colfax CXT5000 PSC GPU Processing with 960 cores and 32GB RAM. The results have been saved after 5 ( sec) flow time simulation to make sure that the fountain reaches a statistically steady state height. Computational model parameters and boundary conditions are summarized in Table 4.

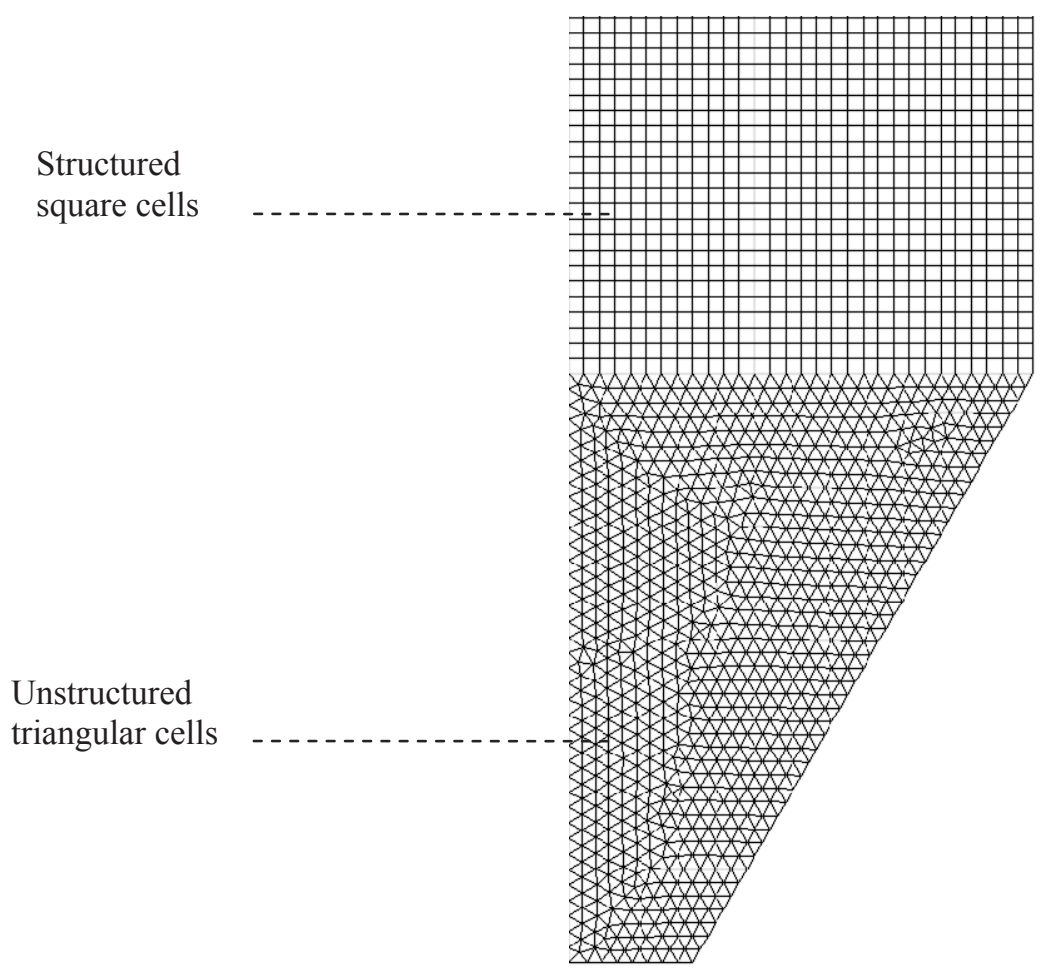

Figure 3: Computational mesh.

\section{Results and discussion}

Simulation results have been compared to the experimental data [1] in order to validate the model. Figure 4 compares the experimental and simulation results for the fountain height as a function of superficial air velocity for a specific operating condition, $(H=0.11(\mathrm{~m}), \mathrm{dp}=0.86(\mathrm{~mm}), \lambda=0.006(\mathrm{~m}))$. As for cylindrical columns [20], the fountain height increases with increasing superficial gas velocity. The figure shows that the slope of the best fit line to data has been well predicted by the model, (Error $<2 \%$ ). However, the numerical simulation overestimates the fountain height at a specific superficial air velocity, (Error $<10 \%$ ). Assumptions and simplifications made in the numerical simulation is one of the main sources of this error. 2D simulation neglects the 


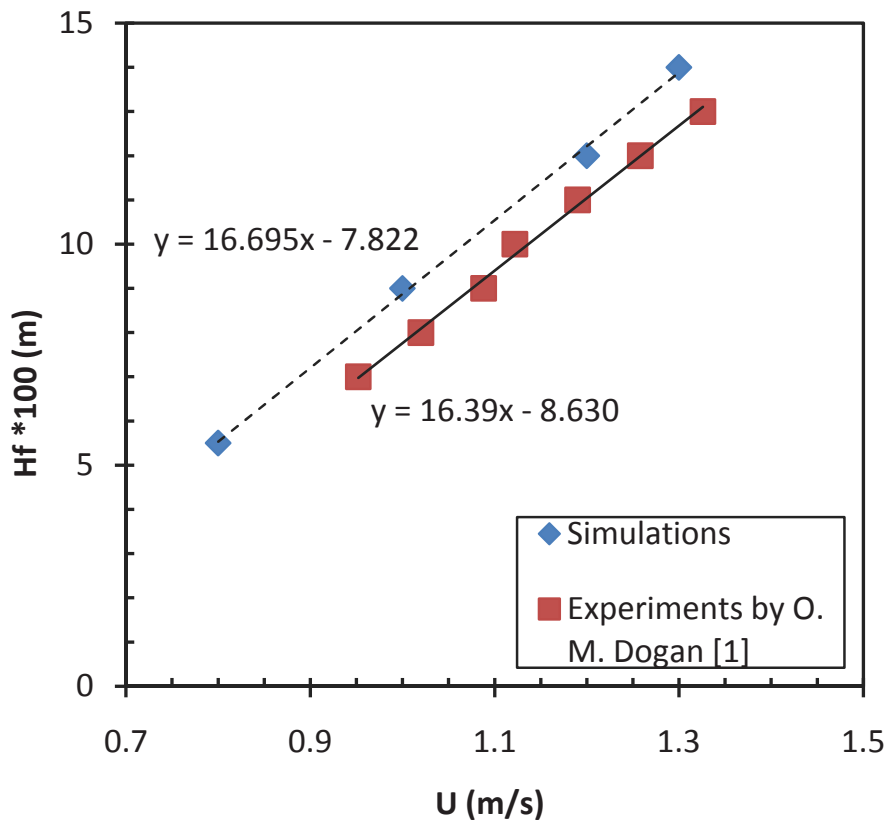

Figure 4: Fountain height as a function of superficial air velocity $(\mathrm{H}=0.11(\mathrm{~m}), \mathrm{dp}=0.86(\mathrm{~mm}), \lambda=0.006(\mathrm{~m}))$.

Upgrading the computational domain for 3D simulations of the bed, variable particle size and density can decrease the computational error to a minimum.

Figure 5 shows the model predictions of fountain height as a function of superficial air velocity for three different slot width, and $(\mathrm{H}=0.11(\mathrm{~m}), \mathrm{dp}=$ $1.44(\mathrm{~mm})$ ). The effect of slot width on the minimum spouting velocity is also shown in this figure. It can be seen that $U_{m s}$, increased with increasing $\lambda$. An increase in $U_{m s}$, with inlet orifice size was previously reported for conical cylindrical columns [3], While, for conical beds, some authors found a decrease in $U_{m s}$ with increasing orifice diameter [3]. The figure also shows that fountain height increases with decreasing slot width which is in a good agreement with experimental data reported by Dogan et al. [1]. This implies that with smaller slot width, higher superficial air velocity will be required to obtain a desired fountain height. Comparing the slope of each line shows that the rate of fountain height increase with superficial air velocity also decreases with increasing slot width.

Figure 6 shows the contour plots of solid volume fraction at different superficial air velocities after $5(\mathrm{sec})$ real-time simulations. It is characteristic for the spouted beds that the fountain forms only after exceeding a certain value of velocity of the gas supplying the device. The transition from the established spouted condition to the fixed bed condition, described by Mathur and Epstein 


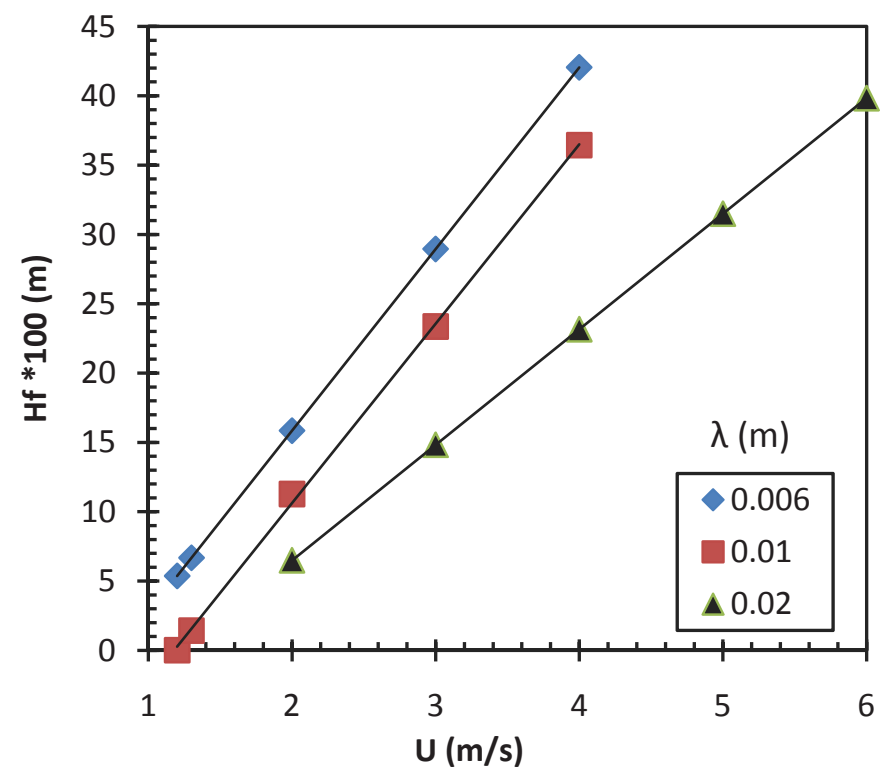

Figure 5: Fountain height as a function of superficial air velocity and slot thickness $(\mathrm{H}=0.11(\mathrm{~m}), \mathrm{dp}=1.44(\mathrm{~mm}))$.

[3], is presented in this figure. The plots also show highest concentration of solid particles in the annulus region, while the fountain and the spout regions have lower concentrations, respectively. These computations allowed determination of the fountain height and the volume distribution of particles in the model. The studies presented here on the influence of supply gas velocity on fountain dynamics are consistent at the qualitative level with the experimental results described in literature [1].

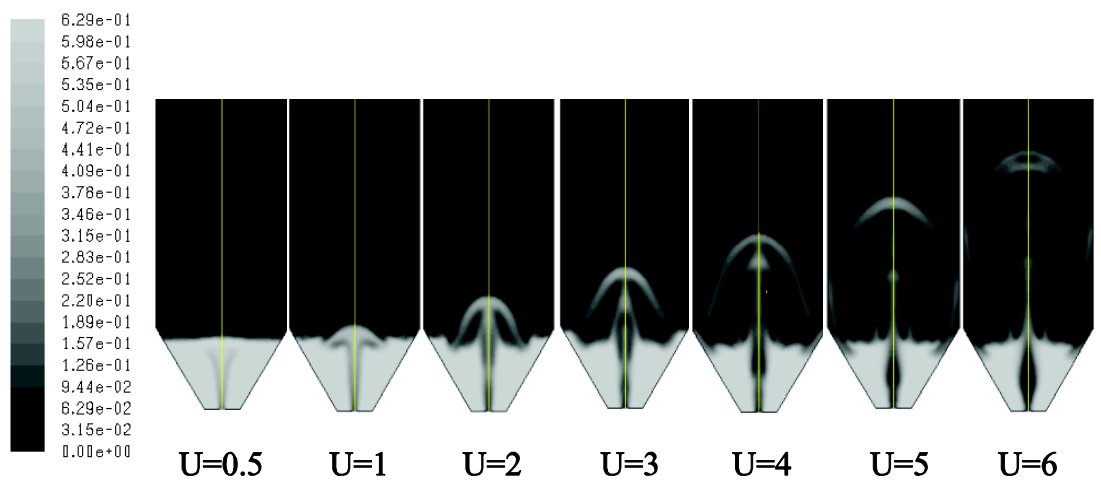

Figure 6: Contours of solid volume fraction for different superficial gas velocity $(\mathrm{H}=0.11(\mathrm{~m}), \mathrm{dp}=1.44(\mathrm{~mm}), \lambda=0.010(\mathrm{~m}))$, (Velocities in $(\mathrm{m} / \mathrm{s}))$. 


\section{Conclusion}

Numerical simulation of a slot rectangular spouted bed have been performed in a 2D axisymmetric solution domain using the Eulerian-Eulerian approach in order to investigate the effect of slot width on the hydrodynamic behaviour of the bed. FLUENT 6.3 was used to perform the calculations. The results show that the fountain height decreases by increasing the slot width at a specific superficial air velocity. The results show a linear relationship between the fountain height and superficial gas velocity. The results predicted by numerical simulation have been validated with the earlier experiments conducted by Dogan et al. [1]. The comparisons have been made in terms of fountain height for various operating conditions, (i.e. different superficial gas velocities, static bed heights, size of particle). The results show a good agreement between the experimental data and the numerical simulation. However, further modeling efforts are required to study the effect of bed thickness using a three dimensional model, and variable size and density distribution of particles in the bed.

\section{Nomenclature}

\begin{tabular}{|c|c|}
\hline$C_{d}$ & Single particle drag function, dimensionless \\
\hline$d_{s}$ & Solid diameter, $\mathrm{m}$ \\
\hline$e$ & Restitution coefficient, dimensionless \\
\hline$g$ & Acceleration due to gravity, $\mathrm{m} / \mathrm{s}^{2}$ \\
\hline$g_{0}$ & Radial distribution coefficient, dimensionless \\
\hline$K_{s g}$ & Gas/solid momentum exchange coefficient, dimensionless \\
\hline$P$ & Pressure, $\mathrm{Pa}$ \\
\hline$P_{S}$ & Solid pressure, $\mathrm{Pa}$ \\
\hline$\vec{V}$ & Velocity, m/s \\
\hline Re & Reynolds number, dimensionless \\
\hline$k_{\Theta_{s}}$ & Conductivity of granular temperature, $\mathrm{kg} /(\mathrm{m} . \mathrm{s})$ \\
\hline \multirow[t]{2}{*}{$\gamma_{\Theta_{s}}$} & Dissipation of granular temperature, $\mathrm{kg} /\left(\mathrm{m} \cdot \mathrm{s}^{3}\right)$ \\
\hline & Greek symbols \\
\hline$\rho$ & Density, $\mathrm{kg} / \mathrm{m}^{3}$ \\
\hline$\Theta_{S}$ & Granular temperature, $\mathrm{m}^{2} / \mathrm{s}^{2}$ \\
\hline$\overline{\bar{\tau}}$ & Stress tensor, $\mathrm{Pa}$ \\
\hline$\mu$ & Shear viscosity, $\mathrm{kg} / \mathrm{sm}$ \\
\hline$\lambda$ & Bulk viscosity, $\mathrm{kg} / \mathrm{sm}$ \\
\hline \multirow[t]{2}{*}{$\varepsilon$} & Volume fraction, dimensionless \\
\hline & Subscripts \\
\hline$g$ & Gas \\
\hline$S$ & Solid \\
\hline
\end{tabular}




\section{References}

[1] Dogan, O. M., Freitas, L. A. P., Lim, C. J., Grace, J. R., Luo, B., "Hydrodynamics and Stability of Slot-Rectangular Spouted Beds. Part I: Thin Bed", Chem. Eng. Comm., (2000), Vol. 181, pp. 225-242.

[2] Mathur, K. B. and P. E. Gishler. "A technique for contacting gases with coarse solid particles", AIChE J. (1955) 1 (2), 157-164.

[3] Mathur, K. B. and N. Epstein, "Spouted Beds", Academic Press, New York, (1974).

[4] Anderson, K., Raghavan, G.S.V, Mujumdar, A.S. "Drying '84", Hemisphere Pub., New York, (1984), pp. 205-209.

[5] Wang, Z. G., Bi, H. T., Lim, C. J., "Numerical simulations of hydrodynamic behaviors in conical spouted beds", Particuology (2006). 4(3-4), 194-203.

[6] Mukhlenov, I. P. and Gorshtein, A. E., "Hydrodynamics of reactors with a spouting bed of granular material", Vses. Konf. Khim. Reactrom Novosibirsk (1965), (3) 553-562.

[7] Kalwar, M. I., Raghavan, G. S. V. and Mujumdar, A. S., Can. J. Chml. Eng. (1992), 70, RR7.

[8] Passos, M. L., Mujumdar, A. S. and Raghavan, G. S. V., Powder Technol. (1993), 74, 97.

[9] Du, W., Bao, X. J., Xu, J., Wei, W. S., “Computational fluid dynamics (CFD) modeling of spouted bed: Assessment of drag coefficient correlations". Chem. Eng. Sci. (2006), 61(5), 1401-1420.

[10] Duarte, C. R., Murata, V. V., Barrozo, M. A. S., "A study of the fluid dynamics of the spouted bed using CFD", Brazilian J. of Chem. Eng. (2005), 22(2), 263-270.

[11] He, Y. R., Zhao, G. B., Bouillard, J., Lu, H. L., "Numerical simulations of the effect of conical dimension on the hydrodynamic behavior in spouted beds", Can. J. Chem. Eng. (2004), 82(1), 20-29.

[12] Huilin, L., Yongli, S., Yang, L., Yurong, H., Bouillard, J., "Numerical simulations of hydrodynamic behaviour in spouted beds", Chem. Eng. Research and Design (2001), 79(A5), 593-599.

[13] Kawaguchi, T., Sakamoto, M., Tanaka, T., Tsuji, Y., "Quasi-threedimensional numerical simulation of spouted beds in cylinder", Powder Technol. (2000), 109 (1-3), 3-12.

[14] Lu, H. L., He, Y. R., Liu, W. T., Ding, J. M., Gidaspow, D., Bouillard, J., "Computer simulations of gas-solid flow in spouted beds using kineticfrictional stress model of granular flow", Chem. Eng. Sci. (2004), 59(4), 865-878.

[15] Shirvanian, P.A., Calo, J.M., Hradil, G., "Numerical simulation of fluidparticle hydrodynamics in a rectangular spouted vessel", International J. of Multiphase Flow (2006), 32, 739-753.

[16] Bettega, R., Correa, R. G., and Freire, J. T., "Scale-Up Study of Spouted Beds Using Computational Fluid Dynamics", The Can. J. of Chem. Eng. (2009), 87, 193-203. 
[17] He, Y. L., Lim, C. J., and Grace, J. R., "Scale-up Studies of Spouted Beds" Chem. Eng. Sci. (1997), 52, 329-339.

[18] Sobieski, W., "Numerical Analysis of Sensitivity of Eulerian Multiphase Model for a Spouted-Bed Grain Dryer", Drying Technol. (2008), 26:12, 1438-1456.

[19] Esmaili, E., "Adjustment of Drag Coefficient Correlations in Three Dimensional CFD Simulation of Gas-Solid Bubbling Fluidized Bed", MS.c Thesis, Dept. of Chem. and Petroleum Eng., University of Calgary, December 2009.

[20] Grace, J. R. and Mathur, K. B. (1978), Height and structure of the fountain region above spouted beds. The Canadian Journal of Chemical Engineering, 56: 533-537. doi: 10.1002/cjce.5450560501. 